\title{
Genital human papillomavirus infection
}

\author{
Douglas R. Lowy, Reinhard Kirnbauer, and John T. Schiller \\ Laboratory of Cellular Oncology, Building 37, Room 1B-26, National Cancer Institute, Bethesda, MD 20892
}

\begin{abstract}
Genital human papillomavirus (HPV) infection is a common serually transmitted disease that at the present time is not eflectively controlled or treated. Many infections are inapparent and transient. However, some HPV infections result in persictent lesions that in some cases undergo carcinogenic progression. A subset of genital HPVs, designated high-risk types, are preferentially associated with high-grade dysplasias and carcinomas. About $90 \%$ of cervical cancers contain high-risk HIV DNA, most often HPV16. Development of a subunit vaccine against high-risk genital HPVs is a desirable and, it appears, an increasingly feasible long-term goal. The viral 56 and 57 oncoproteins are selectively maintained and expressed in progressed HPV tumors and could potentially be targets for therapeutic vaccines. The L1 major virion structural proteins have recently been shown to selfaseemble into virus-like particles when expressed in insect cells. These particles might serve as the basis for a prophylactic vaccine to prevent genital HPV infection.
\end{abstract}

Genital human papillomaviruses (HPVs) induce benign epithelial lesions of the internal and external genitalia and are closely associated with several ano-genital malignancies, especially cervical cancer. HPVs have long been recognized as the etiologic agents of genital and nongenital warts. The involvement of these DNA tumor viruses in so-called flat condylomata of the cervix was recognized in the 1970s (1), which led to their identification in cervical cancers and other malignant genital tumors. Genital HPV infection is almost always sexually acquired, and the epidemiology of cervical cancer follows that of a sexually transmitted condition (see ref. 2 for a review).

Genital HPV infection is not a reportable condition, and the estimates of HPV prevalence vary widely depending upon the detection method used and population studied. Nevertheless, most studies indicate that genital HPV infection is even more common than genital infection with herpes simplex virus. For instance, single point detection prevalence of $>40 \%$ has been found in college women in the United States (3). As with other sexually transmitted diseases, the incidence of genital HPV infection in developed countries increased in recent decades (4). An 8-fold increase in the incidence of genital warts was reported in Rochester between 1950 and 1978 (5).

The close relationship between genital HPV infection and genital malignancies, described below, underscores the potential importance for developing more effective management of this disease. Cervical cancer is the second leading cause of cancer deaths in women worldwide (6). In many developing countries, it is the leading cause of death from cancer in women. In developed countries, the extensive use

The publication costs of this article were defrayed in part by page charge payment. This article must therefore be hereby marked "advertisement" in accordance with 18 U.S.C. $\$ 1734$ solely to indicate this fact. of the Pap (Papanicolaou) smear as a screening test for precursor lesions of the cervix has resulted in a substantial reduction in the incidence of cervical cancer (7). The incidence of cervical cancer may be severalfold higher in developing countries where the Pap smear has been employed more sparingly (2).

\section{Relationship Between HPV Infection and Cervical Cancer}

HPVs cannot be routinely cultivated, and serotypes have not been defined. Instead, HPVs are typed by molecular hybridization of their genomes. By this analysis, $>70$ distinct HPV genotypes (types) have been recognized and defined since the 1970s (8). Significant clinico-pathological correlations can be made for many HPV types. It is useful to divide the HPVs into three broad classes: genital-mucosal types, nongenital types, and epidermodysplasia verruciformis (EV)-specific types. EV is a rare skin condition in which patients develop widespread, chronic nongenital cutaneous HPV lesions (9). Almost one-half of the known HPV types have been identified principally in EV patients. As with other HPV types, the EV-specific types have a worldwide distribution in spite of the small number of EV patients. The nongenital HPV types infect the nongenital skin of the general population and induce common and plantar warts. These lesions have an extremely low probability of oncogenic progression. Clinical infection by the genital-mucosal HPV types (called genital types below) is found most commonly in the internal and external genitalia, although these types may also cause lesions in the upper aerodigestive tract, especially the mouth, pharynx, and larynx.

Two major classes of genital HPV types have been identified, depending upon their association with cervical cancer (reviewed in ref. 10). The "low-risk" types, especially HPV6 and HPV11, are almost never found in cervical malignancies. They are most frequently isolated from external genital warts (condylomata acuminata) or from benign cervical lesions. Viral DNAs from the "high-risk" types, by contrast, are identified in most cervical cancers, although the vast majority of lesions in which they are found are nonmalignant (reviewed in ref. 11). HPV16 and HPV18 are the types most frequently identified in cervical cancers. In most areas, HPV16 is found in 40-60\% of cervical tumors, with HPV18 being present in another 10-20\% (12-15). Most of the remaining tumors contain DNA from other HPV types, such as HPV 31, HPV33, and HPV45. About $10 \%$ of cervical cancers lack detectable HPV DNA.

A wealth of epidemiological and molecular data now provide important evidence for an etiologic relationship between HPV infection and cervical cancer. The molecular data followed the identification of HPV16 and HPV18 in the

Abbreviations: HPV, human papillomavirus; EV, epidermadysplasia verruciformis; BPV, bovine papillomavirus. 
early 1980 s $(16,17)$. Efforts to induce immortalization of human keratinocytes with HPV DNA revealed that the high-risk HPV types scored positive in this assay, while DNA from the low-risk types was negative (18-20). Genetic analysis indicated that efficient keratinocyte immortalization required the E6 and E7 genes from a high-risk HPV type (21-23). This result correlated with the observation that these are the two viral genes that are preferentially retained and expressed in cervical cancers and cell lines derived from these tumors $(24,25)$.

Both E6 and E7 encode multifunctional proteins. Among these functions, the E6 protein binds and degrades the p53 tumor suppressor protein $(26,27)$, while high-risk E7 protein binds the pRB tumor suppressor protein (28). These activities are greater for the proteins from high-risk HPVs than from low-risk HPVs (29-31). The apparent importance of these biochemical activities is underscored by finding that the $R B$ and $p 53$ genes are mutationally inactivated in cervical cancer cell lines that lack HPV, while these genes are wild type in HPV-containing lines (32-34).

Much of the recent epidemiological data linking HPVs and cervical cancer comes from analysis of the relationship between HPV infection and the development of precursor lesions in the cervix. Depending upon the classification scheme, these precursor lesions may be defined as mild, moderate, or severe cervical intra-epithelial neoplasia (CIN 1, CIN 2, and CIN 3, respectively) or low-grade squamous intra-epithelial lesions (SIL), corresponding to CIN 1 , and high-grade SIL, corresponding to CIN 2 and CIN 3 (35). It has been commonly thought that $\mathrm{CIN} 1, \mathrm{CIN} 2$, and $\mathrm{CIN} 3$ represent a morphologic and biologic continuum. However, there is also support for the concept that CIN 1 and CIN 2-CIN 3 are distinct HPV-induced entities with only CIN 2-CIN 3 lesions being true progenitors of cervical cancer (36). Most of the cytologic abnormalities detected in Pap screening are the result of these HPV-induced lesions.

Some earlier epidemiological reports did not identify infection with high-risk HPV types as a major risk factor for cervical cancer precursor lesions. However, these studies appear to have been flawed by false-positive and/or falsenegative viral DNA analysis (37). More recent evaluations, which utilize sensitive and specific polymerase chain reaction (PCR) assays that appear to have overcome earlier methodological difficulties, demonstrate that genital infection with high-risk HPV types is a highly significant risk factor for the development of dysplastic cervical lesions $(38,39)$. These studies estimated that infection with high-risk HPV represents a relative risk of $\mathbf{3 0}$ or greater for the development of high-grade lesions.

The natural history of genital HPV infection has been incompletely analyzed. This is due in large part to the high frequency of subclinical infection and lack of a sensitive and specific serological assay for HPV infection. Molecular hybridization and PCR amplification of DNA from exfoliated cervico-vaginal cells has indicated that genital HPV infection is remarkably frequent. The highest prevalence of HPV is found among sexually active women $<25$ years old. Genital HPV is detected in $\approx 10-40 \%$ of these women. The majority of these infections appear to be self-limited and not to be associated with cytologic changes detectable by routine Pap screening. A minority of HPV-positive women do develop low-grade cytological changes (40-42). High-grade dysplasias, almost all of which are associated with high-risk HPV, are less common, while an even smaller number of women develop invasive cervical cancer. The highest incidence of high-grade lesions occurs in women who are $>25$ years old, while the highest incidence of cervical cancer occurs in women who are $>35$ (42). These findings suggest that highrisk HPVs normally produce a transient inapparent infection of the cervico-vaginal area. Persistent tissue infection devel- ops in some women, perhaps as a result of defects in as yet poorly understood host defense mechanisms. Persistent lesions undergo progression to cervical cancer in a subset of these women.

Although the prevalence of HPV disease in men may be similar to that observed among females, the natural history of genital HPV infection in men is even less well understood. Many lesions are inapparent, fewer exfoliated cells are obtained from penile swabs making HPV DNA detection difficult, and biopsies are seldom obtained. Nevertheless, a strong correlation between genital HPV infection in men and CIN in their regular partners has been documented $(43,44)$. The incidence of penile cancer is much lower than that of cervical cancer and may not be as strongly associated with HPV infection. HPV DNA has generally been detected in 20-50\% of cases (45-47). Anal cancer in both men and women, which is also relatively uncommon, is more strongly associated with HPV infection. In two recent studies using PCR-based detection, HPV DNA was found in $\approx 70 \%$ of cases $(46,48)$.

Patients with cellular immune deficiency have higher rates of HPV infection and tend to respond poorly to therapy (49). In this context, males and females infected with human immunodeficiency virus (HIV) appear to be at greater risk of developing persistent HPV infection, and HIV-positive women with cervical HPV infection are more likely to have high-grade lesions (50).

\section{Management of Genital HPV Lesions}

The management of patients with genital HPV infections remains somewhat controversial (51). In contrast to bacterial sexually transmitted diseases, specific antimicrobial therapy for HPV infection is not yet available. Consequently, most treatment for HPV infection relies on nonspecific therapy such as laser, electrocautery, blistering agents, or agents that interfere with macromolecular synthesis (52). The approach to treatment depends, at least in part, on the goals. If the major purpose is to prevent cervical cancer, then perhaps treatment could be limited to high-grade lesions. This would seem especially true if future studies confirm the suspicion that low-grade lesions are not normally precursors of highgrade lesions. Studies are currently being conducted to determine if high-grade lesions missed by Pap screening and low-grade lesions with greater potential for progression can be effectively identified. At present, DNA typing for highrisk HPVs and cervicography, which produces highresolution photographic images of the cervix, are the most promising ancillary tests (53). Even if these tests prove effective, some would argue it might be more cost effective to treat all cervical lesions (51).

If the goal is to prevent spread of genital infection, it might be appropriate to treat any genital HPV infection. Treatment would apply to men as well as women. Although it may seem reasonable that successful treatment of visible lesions should reduce the spread of HPV infection, there are no studies that document the efficacy of this approach. A study to evaluate the effectiveness of treating infected males found that it had no effect on recurrence rates of cervical dysplasia following treatment in their female partners (54). HPV infection may be multifocal, and some patients may have significant areas of subclinical infection. Furthermore, HPVs have been shown to establish latency in the larynx (55), and HPV DNA has been identified in normal genital epithelium (56). The high prevalence of inapparent HPV infection makes it unclear whether treatment of clinically apparent infection, in the absence of other measures, would have an impact on the rate of genital HPV infection. 


\section{Prospects for Vaccination}

These management considerations highlight the potential utility offered by an effective vaccine against genital HPV infection. Genital HPVs cannot be efficiently propagated. Even if they could, there might be theoretical objections to the use of an attenuated live or inactivated HPV for vaccination, since the HPV genomes contain transforming genes. Attention has therefore focused on the development of a subunit vaccine. Several lines of evidence suggest this may represent a feasible long-term goal (reviewed in ref. 57). Since E6 and E7 are selectively maintained during oncogenic progression, there is the possibility that peptides derived from these oncoproteins could serve as targets for cellmediated immune responses to HPV-containing tumor cells. Some studies in animal models suggest that immunity against E7 (and also against L2) can induce tumor regression (58-60). However, the viral or cellular determinants that are recognized during regression of genital HPV-induced tumors in humans have not been identified. It is also unclear whether therapeutic vaccines will be able to induce an effective immune response in the persistently infected individuals (who appear to be most at risk of developing cancer), since persistence might indicate a constitutive inability to recognize critical viral determinants.

Perhaps the most encouraging experimental vaccine results come from studies of immunoprophylaxis induced by the major and minor structural viral proteins L1 and L2. Studies of the cottontail rabbit papillomavirus and bovine papillomavirus type 1 (BPV1) and type 2 (BPV2) have demonstrated that immunization with these proteins, singly or in combination, prevents experimental infection in vivo (60-62). These studies have used protein produced in bacteria or immunization with vaccinia vectors that express $\mathbf{L 1}$ and/or L2. Immunized animals were protected even when their sera demonstrated neutralizing titers of $<100$. The papillomaviruses in these two animal systems induce cutaneous lesions and are therefore imperfect models for cervical HPV infection. Protection from natural venereal transmis- sion of a genital papillomavirus has not been demonstrated, but rhesus papillomavirus, which infects the genital tract of monkeys, might potentially serve as model to test this possibility.

In our laboratory, we have expressed preparative amounts of the structural viral proteins in insect cells through the use of baculovirus vectors (63). To assess the potential utility of a prophylactic vaccine based on baculovirus-derived virion proteins, we initially used BPV1, since infectious BPV1 can be readily obtained from bovine lesions and a quantitative in vitro BPV1 infectivity assay is available (64). Our BPV1 studies showed that expression of $\mathrm{Ll}$ alone in the insect cells was sufficient for self-assembly of virus-like particles that could readily be purified in preparative amounts (Fig. 1). When rabbits were immunized with the L1 particles, they elicited antisera that could neutralize BPV1 infectivity at a dilution of $1: 100,000$. The neutralizing antibodies were directed against conformational epitopes, in that denaturation of the particles prior to immunization abolished the ability of the preparation to induce neutralizing activity.

When efforts were made to extend this approach to the L1 of HPV16, only rare virus-like particles (three orders of magnitude less than with BPV) were detected when the source of L1 was from the widely used prototype strain of HPV16. Since reasonable self-assembly had also been observed for the low-risk HPV11 L1 (65), this observation suggested either that high-risk HPVs inefficiently selfassemble or that the L1 gene from the HPV16 prototype strain might contain one or more mutations that prevented efficient particle assembly. The latter possibility was given serious consideration, since the HPV16 genome from prototype strain had been molecularly cloned from a cervical cancer, which presumably did not make virus particles. If this speculation were correct, HPV16 L1 from a nonprogressed lesion, which presumably produced virus particles, might self-assemble with greater efficiency. We therefore tested, in collaboration with Matthias Dürst and Lutz Gissmann from the German Cancer Research Center in Heidelberg, the L1 genes from each of two HPV16 genomes that they had cloned

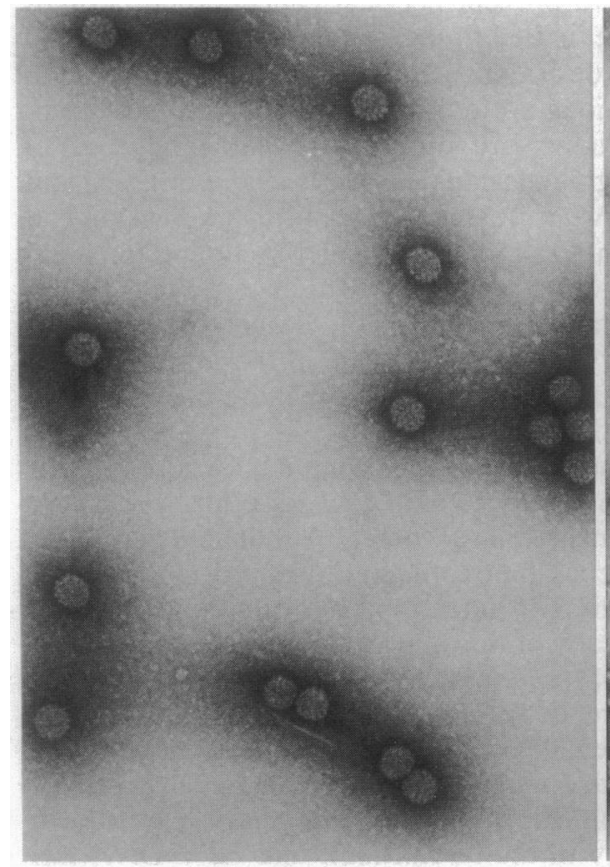

BPV VIRUS

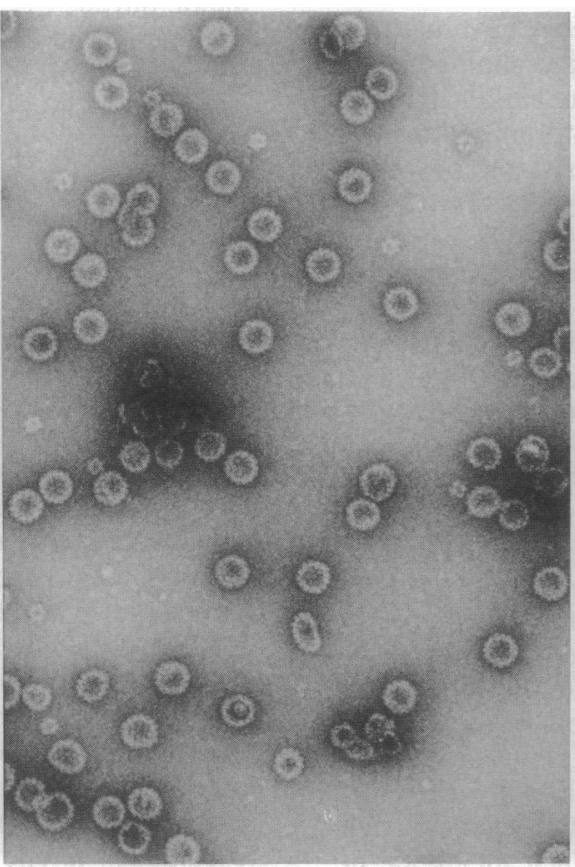

BPV PARTICLES

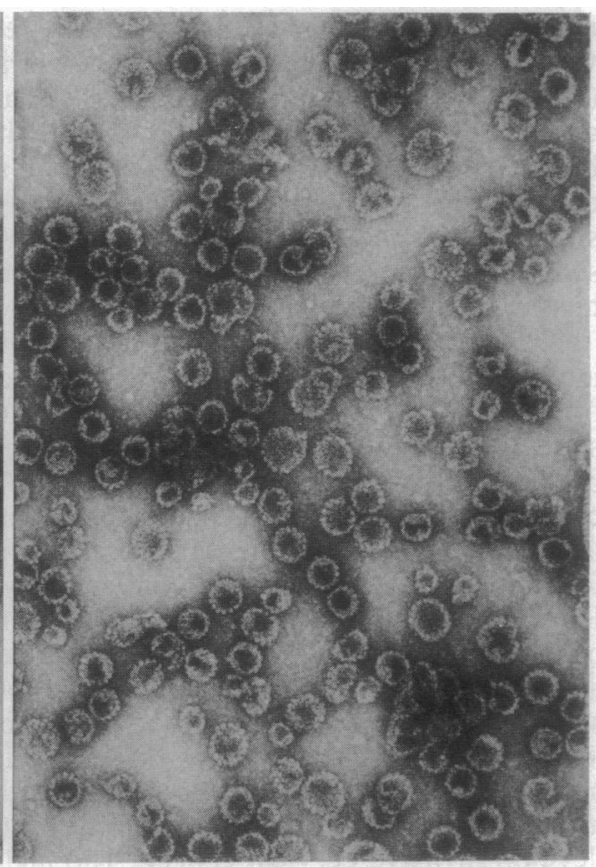

HPV16 PARTICLES

Fig. 1. Purified BPV1 virus and BPV1 L1 and HPV16 L1 virus-like particles. The virus was purified from a bovine papilloma and the particles were purified from recombinant baculovirus-infected insect cells on preparative $\mathrm{CsCl}$ gradients, stained with uranyl acetate, and examined by transmission electron microscopy. $(\times 32,400$. $)$ 


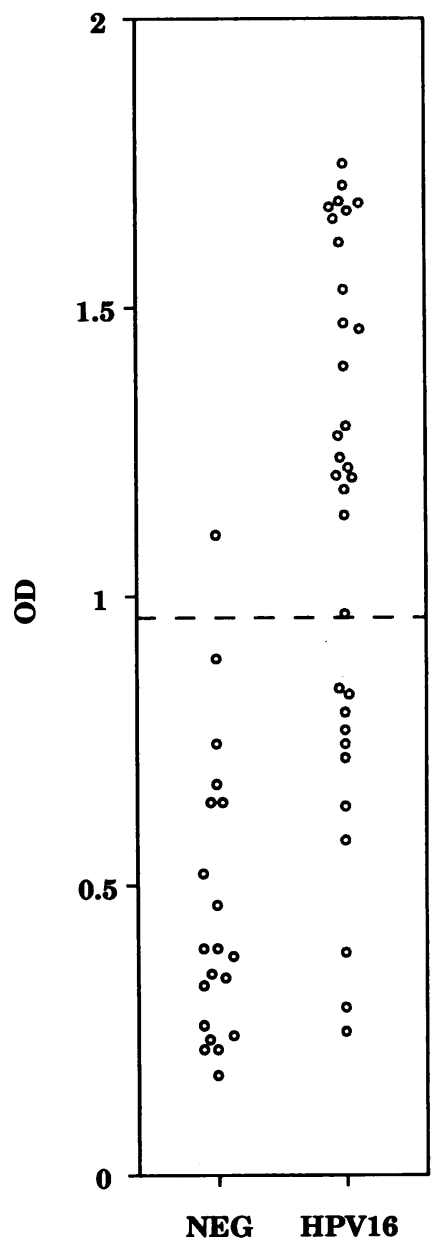

FIG. 2. ELISA reactivity of women's sera to HPV16 L1 viruslike particles. NEG, women negative for HPV DNA; HPV16, women positive for HPV16 DNA. The dashed line indicates the mean plus two standard deviations of the values for the sera from the HPV DNA negative women.

from cases of benign condyloma accuminata. Both of these L1 genes were found to express proteins that self-assembled with an efficiency similar to that of BPV1 L1 (Fig. 1) (66). Sequencing of the $\mathrm{L} 1$ genes from these two genomes revealed that both genes encoded aspartate at codon 202, while L1 from the prototype strain was histidine at this codon. This was the only coding difference between the prototype strain and one of the L1 genes whose protein self-assembled efficiently. These results indicate that the L1 from the HPV16 prototype strain is a mutant and that wild-type HPV16 L1 efficiently self-assembles.

When the L2s from BPV1 and HPV16 were expressed in the insect cells along with their corresponding L1s, they were found to be incorporated into the virus-like particles (66). The presence of L2 in the particles apparently increased the efficiency of particle formation, since HPV16 L1/L2 preparations contained about four times as many particles as those made with L1 only. However, the BPV L1/L2 particles did not induce higher levels of neutralizing activity than BPV L1 particles (unpublished data).

The availability of HPV16 virus-like particles has enabled us to develop, in collaboration with Cosette Wheeler and Thomas Becker from the New Mexico Tumor Registry, an ELISA that detects antivirion serum antibodies in the majority of women who test positive for genital HPV16 DNA. In an analysis of 122 women with known genital HPV DNA status, $63 \%(34 / 54)$ of patients who were positive for HPV16 DNA were positive in the ELISA, while $4 \%(2 / 33)$ of negative controls were positive (67). A representative assay is depicted in Fig. 2. Patients with a higher load of HPV16, as estimated from molecular hybridization, were more likely to be positive in the ELISA. The HPV16 ELISA does not appear to recognize antibodies in patients infected with low-risk HPV types 6 and 11. The reactivity of patients infected with low-risk HPV types 6 and 11 was similar to that of uninfected controls [9\% (1/11)], which suggests that the HPV16 ELISA does not recognize antibodies directed against the virions of low-risk HPV types. Thirty-eight percent of patients who were DNA positive for high-risk HPV types $18(5 / 13)$ and $31(5 / 13)$ scored positive in the ELISA. The latter results suggest either that the $\mathrm{L} 1$ from these types and HPV16 share some cross-reactive conformational epitopes or that a subset of the women with HPV18 or HPV31 infection had been previously infected with HPV16 and remained seropositive.

The development of virus-like particle ELISAs for other HPV types should provide information on the serological relationship between the virions of different HPV types. By using particles from several HPV types, it should be possible to develop an ELISA that recognizes the majority of high-risk HPV infections. The clinical utility of this type of assay remains to be determined, especially since a substantial minority of women with HPV16 infection are negative in the assay. However, these assays should help to determine the extent of antivirion humoral immunity induced during natural genital HPV infections and if there are serological subtypes of HPV16 or other genital HPVs. This information will be important when the components for a multivalent virus-like particle vaccine to prevent genital HPV infection are considered. In addition, the ELISA will be useful to evaluate seroconversion in virus-like particle vaccine trials in animals and, perhaps ultimately, in humans.

1. Meisels, A. \& Fortin, R. (1976) Acta Cytol. 20, 505-509.

2. Brinton, L. A. (1992) in The Epidemiology of Human Papillomavirus and Cervical Cancer, eds. Munoz, N., Bosch, F. X., Shah, K. V. \& Meheus, A. (Int. Agency of Res. on Cancer, Lyon, France), pp. 3-23.

3. Bauer, H. M., Greer, C. E., Chambers, J. C., Tashiro, C. J., Cimera, C. J., Reingold, J. \& Manos, M. M. (1991) J. Am. Med. Assoc. 265, 472-477.

4. States, C. A.-U. (1983) Morbid. Mortal. Wkly. Rep. 32, 306.

5. Chuang, T. Y., Perry, H. O., Kurland, L. T. \& Ilstrup, D. M. (1984) Arch. Dermatol. 120, 469-483.

6. Parkin, D. M., Stjernsward, J. \& Muir, C. S. (1984) Bull. W.H.O. 62, 163-182.

7. Koss, L. G. (1989) J. Am. Med. Assoc. 261, 737-743.

8. de Villiers, E.-M. (1989) J. Virol. 63, 4898-4903.

9. Orth, G. (1987) in The Papovaviridae: The Papillomaviruses, eds. Salzman, N. P. \& Howley, P. M. (Plenum, New York), Vol. 2, pp. 199-243.

10. Werness, B. A., Munger, K. \& Howley, P. M. (1991) in Important Advances in Oncology 1991, eds. DeVita, V. T., Hellman, S. \& Rosenberg, S. A. (Lippincott, Philadelphia), pp. 3-18.

11. zur Hausen, H. \& Schneider, A. (1987) in The Papovaviridae: The Papillomaviruses, eds. Salzman, N. P. \& Howley, P. M. (Plenum, New York), Vol. 2, pp. 245-263.

12. Van den Brule, A. J., Walboomers, J. M. M., du Maine, M., Kenemans, P. \& Meijer, C. J. L. M. (1991) Int. J. Cancer 48, 404-408.

13. Riou, G., Favre, M., Jeannel, D., Bourhis, J., Le Doussal, V. \& Orth, G. (1990) Lancet 335, 1171-1174.

14. Lorincz, A. T., Reid, R., Jenson, A. B., Greenberg, M. D., Lancaster, W. \& Kurman, R. J. (1992) Obstet. Gynecol. 79, 328-337.

15. Higgins, G. D., Davy, M., Roder, D., Uzelin, D. M., Phillips, G. E. \& Burrell, C. J. (1991) Lancet 338, 910-913.

16. Boshart, M., Gissmann, L., Ikenberg, H., Kleinheinz, A., Scheurlen, W. \& zur Hausen, H. (1984) EMBO J. 3, 1153-1157. 
17. Dürst, M., Gissmann, L., Ikenberg, H. \& zur Hausen, H. (1983) Proc. Natl. Acad. Sci. USA 80, 3812-3815.

18. Woodworth, C. D., Doniger, J. \& DiPaolo, J. A. (1989) J. Virol. 63, 159-164.

19. Schlegel, R., Phelps, W. C., Zhang, Y. L. \& Barbosa, M. (1988) EMBO J. 7, 3181-3187.

20. Pecoraro, G., Morgan, D. \& Defendi, V. (1989) Proc. Natl. Acad. Sci. USA 86, 563-567.

21. Hawley-Nelson, P., Vousden, K. H., Hubbert, N. L., Lowy, D. R. \& Schiller, J. T. (1989) EMBO J. 8, 3905-3910.

22. Hudson, J. B., Bedell, M. A., McCance, D. J. \& Laiminis, L. A. (1990) J. Virol. 64, 519-526.

23. Munger, K., Phelps, W. C., Bubb, V., Howley, P. M. \& Schlegel, R. (1989) J. Virol. 63, 4417-4421.

24. Schneider-Gadicke, A. \& Schwarz, E. (1986) EMBO J. 5, 2285-2292.

25. Smotkin, D. \& Wettstein, F. O. (1986) Proc. Natl. Acad. Sci. USA 83, 4680-4684.

26. Scheffiner, M., Werness, B. A., Huibregtse, J. M., Levine, A. J. \& Howley, P. M. (1990) Cell 63, 1129-1136,

27. Werness, B. A., Levine, A. J. \& Howley, P. M. (1990) Science 248, 76-79.

28. Dyson, N., Howley, P. M., Munger, K. \& Harlow, E. (1989) Science 243, 934-937.

29. Barbosa, M. S., Edmonds, C., Fisher, C., Schiller, J. T., Lowy, D. R. \& Vousden, K. H. (1990) EMBO J. 9, 153-160.

30. Crook, T., Tidy, J. A. \& Vousden, K. H. (1991) Cell 67, 547-556.

31. Munger, K., Yee, C. L., Phelps, W. C., Pietenpol, J. A., Moses, H. \& Howley, P. M. (1991) J. Virol. 65, 3943-3948.

32. Wrede, D., Tidy, J. A., Crook, T., Lane, D. \& Vousden, K. H. (1991) Mol. Carcinog. 4, 171-175.

33. Scheffiner, M., Munger, K., Byrne, J. C. \& Howley, P. M. (1991) Proc. Natl. Acad. Sci. USA 88, 5523-5527.

34. Crook, T., Wrede, D. \& Vousden, K. H. (1991) Oncogene 6, 873-875.

35. Workshop, N. C. I. (1989) J. Am. Med. Assoc. 262, 931-934.

36. Kiviat; N. B. \& Koutsky, L. A. (1993) J. Natl. Cancer Inst. 85, 934-935.

37. Franco, E. L. (1991) Epidemiology 2, 98-106.

38. Schiffman, M., Bauer, H. M., Hoover, R. N., Glass, G. A., Cadell, D. M., Rush, B. B., Scott, D. R., Sherman, M. E., Kurman, R. J., Wacholder, S., Stanton, C. K. \& Manos, M. M. (1993) J. Natl. Cancer Inst. 85, 958-964.

39. Koutsky, L. A., Holmes, K. K., Critchlow, C. W., Stevens, C. E., Paavonen, J., Beckmann, A. M., ReRouen, T. A., Galloway, D. A., Vernon, D. \& Kiviat, N. B. (1992) N. Engl. J. Med. 327, 1272-1278.

40. Becker, T. M., Wheeler, C. M., McGough, N. S., Jordan, S. W., Dorin, M. \& Miller, J. (1991) Am. J. Public Health 81, 582-587.

41. de Villiers, E. M., Wagner, D., Schneider, A., Wesch, H., Munz, F., Miklaw, H. \& zur Hausen, H. (1992) Gynecol. Oncol. 44, 33-39.

42. Schiffman, M. H. (1992) J. Natl. Cancer Inst. 84, 394-398.
43. Barrasso, R., de Brux, J., Croissant, O. \& Orth, G. (1987) N. Engl. J. Med. 317, 916-923.

44. Schneider, A., Sawada, E., Gissmann, L. \& Shah, K. (1987) Obstet. Gynecol. 69, 554-562.

45. McCance, D. J., Kalache, A. \& Ashdown, K. (1986) Int. J. Cancer 37, 55-59.

46. Daling, J. R., Sherman, K. J., Hislop, T. G., Maden, C., Mandelson, M. T., Beckman, A. M. \& Weiss, N. S. (1992) Am. J. Epidemiol. 135, 180-189.

47. Maden, C., Sherman, K. J., Beckman, A. M., Hislop, T. G., Teh, C. Z., Ashley, R. L. \& Daling, J. R. (1993) J. Natl. Cancer Inst. 85, 19-24.

48. Crook, T., Wrede, D., Tidy, J., Sholefield, J., Crawford, L. \& Vousden, K. H. (1991) Oncogene 6, 1251-1257.

49. Morison, W. L. (1975) Br. J. Dermatol. 92, 625-630.

50. Judson, F. N. (1992) in The Epidemiology of Human Papillomavirus and Cervical Cancer, eds. Munoz, N., Bosch, F. X., Shah, K. V. \& Meheus, A. (Int. Agency of Res. on Cancer, Lyon, France), pp. 199-207.

51. Richart, R. M. \& Wright, T. C. (1993) Cancer 71, 1413-1421.

52. Beutner, K. R. (1989) J. Am. Acad. Dermatol. 20, 114-123.

53. Solomon, D. (1993) J. Natl. Cancer Inst. 85, 1018-1019.

54. Krebs, H. B. \& Helmkamp, B. F. (1990) Obstet. Gynecol. 76, 660-663.

55. Steinberg, B. M., Topp, W. C., Schneider, P. S. \& Abramson, A. L. (1983) N. Engl. J. Med. 308, 1261-1264.

56. Ferenczy, A., Mitao, M., Nagai, N., Silverstein, S. J. \& Crum, C. P. (1985) N. Engl. J. Med. 313, 784-788.

57. Cason, J., Khan, S. A. \& Best, J. M. (1993) Vaccine 11, 603-611.

58. Chen, L., Thomas, E. K., Hu, S. L., Hellstrom, I. \& Hellstrom, K. E. (1991) Proc. Natl. Acad. Sci. USA 88, 110-114.

59. Meneguzzi, G., Cerni, C., Kieny, M. P. \& Lathes, R. (1991) Virology 181, 62-69.

60. Jarrett, W. F., Smith, K. T., O'Neil, B. W., Gaukroger, J. M., Chandrachud, L. M., Grindlay, G. J., McGarvie, G. M. \& Campo, M. S. (1991) Virology 184, 33-42.

61. Pilacinski, W. P., Glassman, D. L., Glassman, K. F., Reed, D. E., Lum, M. A., Marshall, R. F., Muscoplat, C. C. \& Faras, A. J. (1986) in Papillomaviruses: Ciba Foundation Symposium 120 (Wiley, Chichester, England), pp. 136-156.

62. Lin, Y.-L., Borenstein, L. A., Selvakumar, R., Ahmed, R. \& Wettstein, F. O. (1992) Virology 187, 612-619.

63. Kirnbauer, R., Booy, F., Cheng, N., Lowy, D. R. \& Schiller, J. T. (1992) Proc. Natl. Acad. Sci. USA 89, 12180-12184.

64. Dvoretzky, I., Shober, R., Chattopadhyay, S. K. \& Lowy, D. R. (1980) Virology 103, 369-375.

65. Rose, R. C., Bonnez, W., Reichman, R. C. \& Garcea, R. L. (1993) J. Virol. 67, 1936-1944.

66. Kirnbauer, R., Taub, J., Greenstone, H., Roden, R., Dürst, M., Gissmann, L., Lowy, D. R. \& Schiller, J. T. (1993) J. Virol. 67, 6929-6936.

67. Kirnbauer, R., Hubbert, N. L., Wheeler, C. M., Becker, T. M., Lowy, D. R. \& Schiller, J. T., J. Natl. Cancer Inst., in press. 